\title{
ANALISIS PENERAPAN KARAKTER PEDULI LINGKUNGAN MELALUI PROGRAM SEKOLAH BERBASIS ALAM
}

\section{AN ANALYSIS OF ENVIRONMENTAL CARING CHARACTER APPLICATION THROUGH THE NATURE-BASED SCHOOL PROGRAM}

\author{
A Nurellah'1a, MS Sumantri'1, A Purwanto ${ }^{1}$ \\ 1 Universitas Negeri Jakarta, Jakarta Timur, Indonesia \\ a Korespondensi: Andea Nurellah, Email: andeannurellah@gmail.com \\ (Diterima: 26-07-2018; Ditelaah: 27-07-2018; Disetujui: 14-10-2018)
}

\begin{abstract}
The aim of this study is to determine the application of environmental caring character through nature-based school program in international green school Sumedang. A caring character is an effort to instill environment-based character values that increase the learner's sensitivity to environmental preservation. A nature-based program is a principled learning model on learning about nature, learning to use nature, and learning with nature. The method used in this research is descriptive qualitative research method. The data of this research is the result of observation and interview. The results of the study showed that: (1) the strategy of applying the students' values of environmental caring is applied through selfdevelopment program, integration in the learning environment, school program, and process development, (2) the role of government institution in planning and implementation of environment care cooperation, (3) the application supporting factors of the environmental caring value in the International Green School Sumedang is both school and teachers have done habituation, while the inhibiting factor is the lack of parent cooperation in applying the character of environmental caring at home and the concentration of students are disturbed if the learning activities held in outside the classroom are too crowded.
\end{abstract}

Keywords: character of environmental caring, education, nature-based program.

\begin{abstract}
ABSTRAK
Penelitian ini bertujuan untuk mengetahui penerapan karakter peduli lingkungan melalui program sekolah berbasis alam di internasional green school sumedang. Metode yang digunakan dalam penelitian ini adalah metode penelitian deskriptif kualitatif. Data dari penelitian ini adalah hasil observasi dan wawancara. Hasil dan kesimpulan penelitian mengungkapkan bahwa: (1) strategi penerapan karakter nilai peduli lingkungan siswa diterapkan melalui program pengembangan diri, pengintegrasian dalam mata pelajran, program sekolah,dan pengembangan proses, (2) peran lembaga pemerintah dalam perencanaan dan pelaksanaan penerapan karakter peduli lingkungan yaitu dengan menjalin kerjasama, (3) faktor pendukung penerapan karakter nilai peduli lingkungan di Internasional Green School Sumedang yaitu sekolah dan guru sudah melakukan pembiasaan, sedangkan faktor penghambatnya yaitu kurangnya kerjasama orang tua dalam menerapkan karakter peduli lingkungan di rumah dan konentrasi siswa terganggu apabila situasi pembelajaran yang diakukan di luar kelas terlalu ramai.

Kata kunci: karakter peduli lingkungan, program berbasis alam, pendidikan.
\end{abstract}


Nurellah, A., Sumantri, M. S., \& Purwanto, A. (2018). Analisis Penerapan Karakter Peduli Lingkungan Melalui Program Sekolah Berbasis Alam. Jurnal Sosial Humaniora 9(2): 90-94.

\section{PENDAHULUAN}

Pendidikan adalah suatu upaya yang terencana bertujuan mendewasakan manusia, mengembangkan kemampuan, kekuatan spiritual keagamaan, kecerdasan, akhlak mulia, serta seluruh pontensi yang dimilikinya (Hasan, 2010). Tujuan pendidikan nasional merupakan dasar dalam pengembangan pendidikan budaya dan karakter bangsa. Karakter merupakan sifat-sifat kejiwaan, akhlak atau budi pekerti yang membedakan seseorang dari yang lain. Manusia bergantung pada lingkungan yang memberikan Sumber Daya Alam (SDA) untuk dapat bertahan hidup.

Keterbatasan daya dukung lingkungan, menyebabkan manusia harus dapat memperhatikan dan menjaga lingkungan agar fungsi lingkungan dapat terjaga kelestariaanya dalam mendukung kehidupan di masa yang akan datang. Behavioral belief reflects how important a person considers the outcome of a behavior" (North Chris, 2015). Oleh sebab itu, pendidikan menjadi sangat penting mengingat ketersediaan SDA terbatas. Untuk mengatasi permasalahan tersebut, maka melalui pendidikan manusia bisa mengetahui bagaimana cara mengelola alam dengan baik dan menyesuaikan diri dengan lingkungannya.

Peduli lingkungan adalah sikap dan tindakan yang selalu berupaya mencegah kerusakan pada lingkungan alam disekitarnya, dan mengembangkan upayaupaya untuk memperbaiki kerusakan alam yang sudah terjadi. "Natural resources have been needed, their effectiveness has been limited due to the paucity of available arable land and the frequent conflicts conservation policies have generated among local populations"( Fachruddin Majeri Mangunjaya dan Jeanne Elizabeth McKay, 2012). Oleh sebab itu, dalam mengembangkan nilai peduli lingkungan pada siswa, diperlukan suatu pengkondisian dimana nantinya siswa akan terbiasa dan terlatih untuk memunculkan perilaku dan sikap yang dapat menjaga lingkungan.

Internasional Green School merupakan sekolah dasar karakter berbasis alam dan teknologi dengan memadupadankan antara karakter, alam, dan teknologi. Metode sekolah alam yang diintegrasikan dengan kurikulum nasional yang menyisipkan pembentukan 32 karakter di setiap SubFokus pembelajarannya, juga program pengembangan diri dan muatan internasioanal yang dikemas dengan kekhasan Internasional Green School.

Internasional Green School menjadikan alam sebagai kelas, alam sebagai ilmu, dan alam sebagai laboratorium. Beberapa program berbasis alam yang terdapat di Internasional Green School di antaranya, yaitu pembelajaran harus $75 \%$ di luar ruangan, dan kolaboasi dengan dinas pemerintahan, bank sampah IGS. Oleh karena itu, peneliti tertarik untuk membuat sebuah penelitian dengan studi kasus, yang akan mengungkapkan dan mengembangkan pembentukan nilai karakter peduli lingkungan siswa yang berjudul "Analisis Penerapan Karakter Peduli Lingkungan Melalui Program Sekolah Berbasis Alam Di Internasional Green School Sumedang".

Adapun yang menjadi subfokus dalam penelitian ini diantaranya:

1. Strategi penerapan karakter nilai peduli lingkungan siswa di Internasional Green School melalui program berbasis alam.

2. Peran lembaga pemerintah dalam perencanaan dan pelaksanaan penerapan karakter nilai peduli lingkungan siswa di Internasional Green School melalui program berbasis alam.

3. Faktor pendukung dan penghambat dalam penerapan karakter nilai peduli lingkungan siswa di Internasional Green School melalui program berbasis alam. 
Berdasarkan fokus penelitian di atas, maka rumusan masalah dalam penelitian ini adalah:

1. Bagaimana strategi penerapan karakter nilai peduli lingkungan siswa di Internasional Green School melalui program berbasis alam?

2. Bagaimana peran lembaga pemerintah dalam perencanaan dan pelaksanaan penerapan karakter nilai peduli lingkungan siswa di Internasional Green School melalui program berbasis alam?

3. Apa saja faktor pendukung dan penghambat dalam penerapan karakter nilai peduli lingkungan siswa di Internasional Green School melalui program berbasis alam?

\section{MATERI DAN METODE}

Metode penelitian yang digunakan dalam penelitian ini adalah pendekatan deskriptif kualitatif. Instrumen atau alat penelitian dalam penelitian kualitatif adalah peneliti itu sendiri. Peneliti harus memahami metode penelitian kualitatif, penguasaan wawasan terhadap bidang yang akan diteliti, dan kesiapan peneliti untuk masuk ke dalam objek penelitian. Hal tersebut di anggap perlu sebagai bentuk validasi instrumen yang dilakukan oleh peneliti sendiri.

Teknik observasi digunakan untuk memperoleh data secara langsung. Observasi dilaksanakan di Internasional Green School. Teknik observasi partisipasi dibedakan menjadi pasif, moderat, aktif, dan lengkap. Dari beberapa macam teknik tersebut, peneliti memilih menggunakan observasi partisipasi pasif dimana peneliti datang di tempat kegiatan orang yang diamati, tetapi tidak ikut terlibat dalam kegiatan tersebut (Sugiyono, 2014). Peneliti melakukan observasi dengan mengamati secara langsung pelaksanaan pendidikan karakter peduli lingkungan di Internasional Green School setiap hari. Peran pemerintah dalam perencanaan dan pelaksanaan pembentukan karakter siswa, dan faktor pendukung dan penghambatnya. Dalam pengambilan data dengan teknik observasi menggunakan berbagai macam cara bentuk pengumpulan data yaitu wawanara, dan dokumentasi.

\section{HASIL DAN PEMBAHASAN}

\section{Strategi Penerapan Karakter Peduli Lingkungan}

\section{Program Pengembangan Diri}

\section{Kegiatan Rutin Sekolah}

Kegiatan rutin sekolah dalam menanamkan pendidikan karakter peduli lingkungan adalah dengan melakukan gardening dan kegiatan Jumsih. Kegiatan piket yang dilaksanakan baik piket guru dan piket siswa. Kegiatan Jumsih berupa kegiatan membersihkan halaman sekolah yang melibatkan seluruh warga sekolah, pramuka, Cooking Class, dan Reading Time. Kerja bakti dilaksanakan oleh seluruh siswa, guru, dan kepala sekolah. Kegiatan rutin sekolah dilaksanakan dengan mengoptimalkan sarana dan prasarana yang ada di sekolah untuk mencapai tujuan pendidikan yang diharapkan sekolah

\section{Kegiatan Spontan}

Kegiatan spontan yang dilakukan kepala sekolah dan guru pada siswa yang berprilaku kurang baik terhadap fasilitas adalah dengan memberi Treatment, pemahaman, disiplin positif, ditegur, di nasehati, dan menghubungi orang tua jika ada yang rusak kecuali untuk keperluan belajar. Ivan Pavlov mengemukakan perilaku dikontrol dengan pengkondisian lingkungan, oleh karena itu belajar merupakan proses pemberian stimulus dan respon. Hal serupa dikemukakan oleh Bronfenbrenner, perkembangan dipengaruhi oleh beberapa sistem lingkungan termasuk di dalamnya aturan atau kejadian yang ada di lingkungan tersebut. 


\section{Keteladanan}

Keteladanan kepala sekolah dan guru kepada siswa dalam pelaksanaan pendidikan peduli lingkungan antara lain adalah kepala sekolah dan guru senantiasa meneladankan sikap peduli terhadap lingkungan, menjaga kebersihan, menempatkan alat belajar sesuai dengan tempatnya, merawat dan menjaga fasilitas sekolah, dan ikut terlibat langsung dalam kegiatan sekolah. Keteladan juga didukung oleh sarana dan prasarana sekolah yang memadahi dalam pelaksanaan pendidikan karakter peduli lingkungan agar tujuan pendidikan untuk membentuk manusia yang berkarakter dapat tercapai. Sebagaimana Jean Piaget mengidentifikasi empat faktor dalam perkembangan kognitif seseorang yaitu biological maturation, activity, social experiences, and equilibration.

\section{Pengondisian}

Pengkondisian yang dilakukan sekolah dalam melaksanakan pendidikan karakter peduli lingkungan adalah dengan meyeiakan semua kebutuhan siswa yang berkaitan dengan kebutuhan lingkungan. Sekolah mengupayakan fasilitas alat kebersihan sebanyak dan selengkap mungkin, serta menempatkan alat kebersihan di tempat yang mudah dijangkau oleh seluruh warga sekolah. Menkondisikan toilet dalam keadaan selalu bersih setiap hari. Sekolah selalu melibatkan sswa dalam penataan tanaman, pengolahan maupun peawatan tanaman di sekolah. Sarana dan prasarana yang memadai akan membantu pelaksanaan pendidikan karakter peduli lingkungan apabila digunakan secara optimal oleh warga sekolah. Sebagaimana yang dikemukakan oleh Vigotsky, belajar merupakan proses konstruksi pengetahuan, namun peran lingkungan dan interaksi sosial ikut menentukan.

\section{Pengintegrasian dalam Mata Pelajaran}

Pengintegrasian yang dilakukan sekolah dalam melaksanakan pendidikan karakter peduli linkungan adalah dengan memenuhi segala kebutuhan siswa yang berkaitan dengan kebutuhan lingkungan. Sarana dan prasarana yang disediakan sekolah cukup lengkap. Kepala sekolah dan guru berperan aktif dalam melakukan pengkondisian. Siswa dapat mengoptimalkan pengondisian yang diberikan untuk membantu proses pembelajaran.

\section{Peran Lembaga Pemerintah}

Peran lembaga pemerintah dalam perencanaan dan pelaksanaan pembentukan karakter nilai peduli lingkungan siswa di Internasional Green School Sumedang yakni dengan cara membentuk kerjasama. Baik pihak sekolah yang mengajukan surat permohonan kunjungan atau sebaliknya. Sekolah dilibatkan dalam kegiatan yang dilaksanakan oleh pemerintah. Sehingga program pemerintah yang sudah dirancang sebelumnya dapat terlaksana dengan baik sesuai harapan. Ataupun sebaliknya, sekolah melibatkan pemerintah untuk melaksanakan program pembelajaran yang sudah rancang sebelumnya.

\section{Faktor Pendukung dan Penghambat}

Faktor pendukung dalam pembentukan karakter nilai peduli lingkungan lingkungan siswa di Internasional Green School Sumedang yaitu sekolah dan guru sudah melakukan pembiasaan di sekolah. Seperti mengintegrasikan karakter peduli lingkungan dengan mengimplementasikannya pada indikator setiap mata pelajaran. Sedangkan faktor penghambat dalam pembentukan karakter nilai peduli lingkungan lingkungan siswa di 
Internasional Green School Sumedang yaitu kurangnya kerjasama antara yang sudah dipelajari siswa disekolah dengan kegiatannya di rumah bersama orang tua, serta konsentrasi siswa yang terganggu apabila lingkungan belajarnya di luar kelas terlalu ramai.

\section{KESIMPULAN DAN IMPLIKASI}

Berdasarkan hasil penelitian dan pembahasan, maka penelitian ini dapat disimpulkan bahwa pengembangan karakter nilai peduli lingkungan melalui program berbasis alam di Internasional Green School Sumedang melalui sebagai berikut.

1. Strategi pengembangan karakter nilai peduli lingkungan siswa di Internasional Green School Sumedang melalui program berbasis alam, meliputi program pengembangan diri, pengintegrasian dalam mata pelajaran, dan budaya sekolah. Program pengembangan diri meliputi kegiatan rutin, kegiatan spontan, keteladanan kepala sekolah dan guru, pengkondisian dalam mendukung pelaksanaan pendidikan karakter peduli lingkungan. Pengintegrasian dalam mata pelajaran dilakukan guru dengan cara mengintegrasikan nilai peduli lingkungan dalam mata pelajaran tertentu dengan menyusun programprogam sekolah yang berkaitan dengan pengembangan karakter peduli lingkungan dan turut hadir pada kegiatan pemerintah dalam proses mewujudkan karakter peduli lingkungan. Pengembangan kurikulum sekolah dilakukan dengan cara mengoptimalkan sarana dan prasarana yang disediakan sekolah untuk menunjang program yang disusun sekolah demi tercapainya tujuan pendidikan.

2. lembaga pemerintah sangat mendukung dalam perencanaan dan pelaksanaan pembentukan karakter nilai peduli lingkungan siswa di Internasional Green School Sumedang. Salah satunya yakni dengan membentuk kerjasama. Seperti mengajukan surat permohonan bibit pohon untuk melalukakan reboisasi di hari pohon dunia. Sekolah terlibat dalam kegiatan peingatan hari pohon yang dilaksanakan oleh Dinas Kehutanan. Ataupun sebaliknya, pemerintah dilibatkan sekolah untuk melaksanakan program pembelajaran yang sudah rancang sebelumnya.

3. Faktor pendukung dalam pembentukan karakter nilai peduli lingkungan lingkungan siswa di Internasional Green School Sumedang yaitu sekolah dan guru sudah melakukan pembiasaan penerapan arakter peduli lingkungan di sekolah. Sedangkan faktor penghambat dalam pembentukan karakter nilai peduli lingkungan lingkungan siswa di Internasional Green School Sumedang yaitu kurangnya kerjasama antara yang sudah dipelajari siswa disekolah dengan kegiatannya di rumah bersama orang tua, serta konsentrasi siswa yang terganggu apabila lingkungan belajarnya di luar kelas terlalu ramai.

\section{DAFTAR PUSTAKA}

Hasan, Said Hamid. dkk. (2010). Pengembangan Pendidikan Budaya dan Karakter Bangsa. Jakarta: Kementerian Pendidikan Nasional Badan Penelitian dan Pengembangan Pusat Kurikulum.

Mangunjaya, Fachruddin Majeri dan Jeanne Elizabeth McKay. (2012). Reviving an Islamic Approach for Environmental Conservation in Indonesia. Vol. 16, No. 3, p. 286-305.

North, Chris. (2015) Rain and Romanticism: the environment in outdoor education. Vol. 6. p. 287-298.

Sugiyono. (2013). Metode Penelitian Kuantitati, Kualitatif dan R \& D. Bandung: Alfabeta. 